\title{
Arte-mediação: proposta outra para pensar mediação "cultural" no ensino de Arte ${ }^{1}$
}

\author{
Arte-mediación: propuesta otra para pensar mediación "cultural" en el \\ enseño del Arte
Art-mediation: another proposal to think "cultural" mediation in Art teaching

\author{
Kelly Queiroz dos Santos ${ }^{2}$
}

Marcos Antônio Bessa-Oliveira ${ }^{3}$

\begin{abstract}
Resumo
Este trabalho deseja (re)verificar os conceitos já estabelecidos de Mediação Cultural por pesquisadores de diversas áreas: teatro, dança e artes visuais. Esta necessidade surge ao entender que não é possível mediar culturas, mas o que se dá é uma troca de conhecimentos culturais, e a proposta aqui entendida como Mediação Artística - devido ao processo de (re)verificação do próprio conceito de Mediação "Cultural", escolho em minha pesquisa chamar de "Artística" - se refere, em primeira instância, à criação de abordagens epistemológicas artístico-pedagógicas que visam a aproximação entre artista e espectador. A Arte-mediação aqui apresentada deseja ir além do objetivo da aproximação do sujeito-estudante das obras artísticas com seus respectivos artistas e da sensibilização prévia para a apreciação de uma produção artística específica. Com a Arte-mediação desejamos uma aproximação no ensino de Arte entre estudante, professor e conteúdo escolar, mas também ainda, após a mediação entre os sujeitos sociais do ensino de Arte, aproximar os estudantes de artistas e suas produções. Para (re)verificar a mediação "cultural" faz-se necessário discutir epistemologicamente os conceitos de Arte, Cultura, Educação e Conhecimento, utilizando-se, principalmente, de autores de perspectiva descolonial, para construir um pensamento outro sobre os conceitos em discussão, indo além dos já estabelecidos, mesmo que no imaginário social, pela colonialidade. Desejamos compreender a arte, a cultura, a educação, os conhecimentos e a mediação por uma perspectiva teórico-crítica cultural contemporânea, ancorada na ideia de que todo sujeito, lugar e narrativa fazem emergir conhecimento, utilizando uma abordagem bibliográfica que dialoga com as experiências em mediação da autora.
\end{abstract}

Palavras-Chave: Arte; Cultura; Educação; Mediação.

\section{Resumen}

\footnotetext{
${ }^{1}$ Artigo apresentado no I Congresso Internacional Online de Estudos sobre Culturas, na modalidade online, 2019. Este artigo é recorte de uma pesquisa de Mestrado que estou desenvolvendo no Programa de PósGraduação Stricto Sensu Mestrado Profissional em Educação (PROFEDUC) na Universidade Estadual de Mato Grosso do Sul (UEMS) Unidade Universitária de Campo Grande - MS cujo título é "Arte-mediação: uma proposta outra para pensar mediação "cultural" no ensino de Arte".

${ }^{2}$ Licenciada em Artes Cênicas e Dança, Mestranda em Educação; Universidade Estadual de Mato Grosso do Sul; Campo Grande, Mato Grosso do Sul, Brasil; kellyq.santos@gmail.com.

${ }^{3}$ Doutor em Artes Visuais (Fundamentos Teóricos); NAV(r)E/UEMS - Curso de Artes Cênicas-Licenciatura e PROFEDUC; Campo Grande, Mato Grosso do Sul - Brasil; marcosbessa2001@ gmail.com.
} 
Este trabajo desea (re) verificar los conceptos ya establecidos de Mediación Cultural por investigadores de diferentes áreas: teatro, danza y artes visuales. Esta necesidad surge cuando entendemos que no es posible mediar culturas, pero lo que sucede es un intercambio de conocimiento cultural, y la propuesta aquí entendida como Mediación Artística - debido al proceso de (re)verificación del concepto mismo de Mediación "Cultural", elijo en mi investigación llamar "Artístico" - se refiere, en primera instancia, a la creación de enfoques epistemológicos artístico-pedagógicos que tienen como objetivo acercar a artistas y espectadores. La mediación artística presentada aquí desea ir más allá del objetivo de acercar al sujeto-estudiante de obras artísticas a sus respectivos artistas y crear conciencia antes de apreciar una producción artística específica. Con la Artmediación queremos un enfoque en la enseñanza del arte entre el contenido del alumno, el maestro y la escuela, pero también, después de la mediación entre las asignaturas sociales de la enseñanza del arte, acercar a los alumnos a los artistas y sus producciones. Para (re)verificar la mediación "cultural", es necesario discutir epistemológicamente los conceptos de Arte, Cultura, Educación y Conocimiento, utilizando principalmente autores desde una perspectiva descolonial, para construir otro pensamiento sobre los conceptos en discusión, yendo más allá de los ya establecidos, incluso en la imaginación social, por la colonialidad. Deseamos entender el arte, la cultura, la educación, el conocimiento y la mediación desde una perspectiva cultural-teórica contemporánea, anclados en la idea de que cada sujeto, lugar y narrativa surgen conocimiento, utilizando un enfoque bibliográfico que dialoga con experiencias en la mediación del autor.

Palabras claves: Arte; Cultura; Educación; Mediación.

\begin{abstract}
This work wishes to (re)verify the already established concepts of Cultural Mediation by researchers from different areas: theater, dance and visual arts. This need arises when we understand that it is not possible to mediate cultures, but what happens is an exchange of cultural knowledge, and the proposal here understood as Artistic Mediation - due to the process of (re)verification of the very concept of "Cultural" Mediation, I choose in my research to call "Artistic" - it refers, in the first instance, to the creation of artistic-pedagogical epistemological that aim the approximation between artist and spectator. The Art-mediation presented here wishes to go beyond the objective of bringing the student-subject of artistic works closer to their respective artists and raising awareness to the appreciation of a specific artistic production. With Art-mediation we want an approximation in Art teaching between student, teacher and school content, but also, after mediation between the social subjects of Art teaching, to bring students closer to artists and their productions. In order to (re)verify "cultural" mediation, it is necessary to epistemologically discuss the concepts of Art, Culture, Education and Knowledge, using mainly authors from a decolonial perspective, to build another thought on the concepts under discussion, going beyond those already established, even if in the social imagination, by coloniality. We wish to understand art, culture, education, knowledge and mediation from a contemporary cultural theoretical-critical perspective, anchored on the idea that every subject, place and narrative emerge knowledge, using a bibliographic approach that dialogues with experiences in mediation by the author.
\end{abstract}

Key words: Art; Culture; Education; Mediation.

\title{
Sobre a Arte-mediação e as (re)verificações
}

Este trabalho, a partir de uma perspectiva descolonial, deseja desenvolver uma proposta de Arte-mediação a partir de pesquisas, produções e experiências da autora em mediação cultural, com o objetivo de aproximar e facilitar a relação social entre os sujeitos da educação e o ensino-aprendizagem de Arte. A proposta surge ao refletir sobre a situação em que o ensino de Arte hoje se encontra e como está posta a relação entre esses sujeitos e a educação. 
Encontramos referenciais para a educação apenas pautados na História da Arte, conteúdo baseado na modernidade/colonialidade e pelo eurocentrismo. A História da Arte contada, ensinada e reproduzida há anos na Educação Formal é a história da Europa, que não dialoga com a história da Arte do lugar onde o sujeito da educação está, como, por exemplo, o lócus de onde falo: Mato Grosso do Sul. Tal distanciamento com o conteúdo ministrado pelo professor acaba por distanciá-lo do estudante, que não se identifica com o tema e que, indireta ou diretamente, não se identifica com o professor, que em grande parte não está proporcionando diálogos entre ele, estudante e conteúdo.

A discussão acerca da Arte-mediação emerge do momento em que eu apresento como trabalho de conclusão de curso (TCC) em Artes Cênicas e Dança (2017), na Universidade Estadual de Mato Grosso do Sul (UEMS), o tema "Mediação cultural dialogando com a dança e a educação". Naquela pesquisa são apresentados os conceitos de mediação cultural a partir de pesquisadores de diferentes linguagens artísticas, abordando a mediação cultural nas Artes Cênicas, sempre trazendo para a discussão minhas experiências práticas, e também o caráter pedagógico da mediação cultural como possibilidade de trabalho no ensino de Arte, especificamente no ensino de Dança na educação formal, nos anos iniciais, ao dialogar com os PCN's de Arte e a abordagem triangular de Ana Mae Barbosa que discute o ensino de Arte a partir das Artes Visuais.

Foi a partir da pesquisa de TCC e da participação como aluna especial na disciplina de Itinerários Culturais-2018 - cujo tema era "Arte Cultura e Educação na Formação Docente com perspectivas dos Estudos de Culturas" - no Programa de Pós-Graduação Stricto Sensu Mestrado Profissional em Educação da UEMS, que surgiu a necessidade maior de (re)verificar o conceito de mediação cultural como está posta nas disciplinas. Esse desejo se dá ao entender que toda mediação está no campo cultural; pois todos os sujeitos são culturais, o que fez perceber tamanha complexidade que poderia ser "mediar culturas"

O caráter pedagógico da mediação "cultural" - aqui constando entre aspas pelo processo de (re)verificação do conceito que este trabalho quer propor e usar de mediação artística como conceito - foi percebido durante minha primeira experiência como Arte-

\footnotetext{
${ }^{4}$ Apresenta-se essa complexidade ao entender que não se media culturas, o que acontece são trocas de conhecimentos. Mediar culturas parece evidenciar que uma é melhor ou menor que a outra e a proposta aqui de Arte-mediação refere-se a um lugar de troca de conhecimentos entre professores e estudantes, levando em consideração conteúdos, artistas e práticas culturais diferentes. Logo, aproximação daquilo que é desconhecido do estudante ao que é intrinsecamente seu e vice-versa, por exemplo, a fim de reforçar que tanto suas práticas culturais são importantes no contexto escolar como produção de conhecimentos, assim como o são as práticas de outras culturas sempre presentes na escola.
} 
educadora no Festival do Teatro Brasileiro em 2014. Foram realizadas oficinas em escolas públicas de Campo Grande/MS para que os estudantes fossem apreciar um espetáculo teatral. Naquele momento, percebendo o que estava sendo reverberado nos estudantes, vi que aquela ação deveria se dar em outros momentos e na maior quantidade de escolas possíveis para que os estudantes pudessem ter a experiência da apreciação de obras artísticas, e assim seria feita também uma possível formação de público. Enquanto futura professora de Arte, sabia que isso deveria ser feito, principalmente, no ensino de Arte da Educação Formal.

Foi através das discussões e da percepção do caráter pedagógico da mediação que emergiu o desejo de (re)verificar também as relações já postas entre sujeitos e as demandas atuais do ensino de Arte, sendo eles: o professor, o estudante e o conteúdo escolar; entendendo que a então proposta de Arte-mediação pode apresentar uma reflexão outra mediada sobre essa relação, propondo uma aproximação entre os sujeitos envolvidos professor e estudante - e o conteúdo escolar para além do que nos é apresentado cotidianamente por meio da exclusividade da historiografia da arte europeia.

Para apontar concretude de tal proposta aqui suscitada será necessário trazer para a discussão os conceitos até então apresentados na cultura escolar de Arte, Cultura, Educação, Conhecimento e Mediação a fim de (re)verificá-los. Será feita tal reflexão e discussão levando em consideração pesquisas de diferentes áreas e linguagens artísticas, para então propor a Arte-mediação para o ensino de Arte e, a partir de tais (re)verificações, apresentar pensamentos epistêmicos outros baseados em uma perspectiva descolonial.

Olhar para os conceitos de arte, cultura, educação, conhecimento e mediação cultural a partir da perspectiva descolonial me proporcionará olhares outros para além dos já estabelecidos e instaurados pela modernidade/colonialidade e pelo eurocentrismo. É urgente (re)verificar tais conceitos e as relações entre os sujeitos do ensino-aprendizagem em Arte e o conteúdo escolar a partir do colonizado, do subalterno, que não é reconhecido pela perspectiva eurocêntrica, promovendo todo sujeito como produtor de arte, cultura e conhecimento a partir das suas especificidades biogeográficas (BESSA-OLIVEIRA, 2017).

\section{Arte-mediação: uma proposta de (re)verificações}

Esta pesquisa busca diversas (re)verificações epistemológicas acerca dos conceitos de Arte, Cultura, Educação, Conhecimento e Mediação a partir de uma perspectiva descolonial, objetivando um pensamento epistêmico outro de conceitos já postos e estabelecidos nas culturas ocidentais - em sua maioria - por um discurso eurocêntrico. Para contemplar esta 
proposta de reflexão, de (re)verificação ${ }^{5}$ dos conceitos de mediação cultural, arte, cultura, educação e conhecimento, além das relações entre estudante, professor e conteúdo escolar, lanço mão, portanto, de epistemologias que estão pensando as culturas fora da imposição modernidade/colonialidade e pelo lócus enunciativo com exclusividade no eurocentrismo.

Já dentre os autores pesquisados para tratar do conceito de mediação cultural nas diferentes linguagens lanço mão de Flavio Desgranges, pesquisador do Teatro, citado por Glauber Gonçalves (2003, apud, ABREU, 2014, p. 61), ao dizer que "é considerado procedimento de mediação toda e qualquer ação que se interponha, situando-se no espaço existente entre palco e plateia, buscando possibilitar ou qualificar a relação do espectador com a obra teatro". A ideia do autor sobre os procedimentos de mediação dialoga diretamente com a Arte-mediação, uma ação situada entre palco e plateia, ou seja, entre a Arte e o estudante, com o objetivo de aproximá-los, de proporcionar relações entre estudante e as aulas de Arte, automaticamente entre professor e conteúdos assim como o é o proposto entre artista e espectador na visão do autor.

Zina Filler (2015, p. 135), pesquisadora da Dança, afirma que "Estamos todos, o tempo todo, nas intersecções de uma complexa rede de conhecimentos, desejos, histórias passadas e presentes tentando construir narrativas e diálogos que criem sentidos para nós e para o contexto no qual estamos inseridos". A autora diz isso ao fazer a distinção entre mediação natural e cultural, afirmando que a mediação cultural está "no campo da cultura e mais especificamente no campo da gestão cultural, ele (o processo de mediação) demanda planejamento, diferentes estratégias, olhar atento para o contexto, seu tempo e para as pessoas que por esta 'paisagem' transitam” (FILLER, 2015, p. 135).

E foi a partir da colocação de Zina Filler, da diferenciação entre mediação natural e cultural que surgiram diversas problemáticas acerca do conceito de mediação cultural, especialmente ao entender que todos os seres são culturais, então até a mediação feita por nossos pais e professores que acontece naturalmente é cultural. Logo, então, se media cultura? De que forma ainda é possível falarmos em mediar conhecimentos culturais sem ressaltar a superioridade de uma cultura em detrimento de outras? ${ }^{6}$

\footnotetext{
${ }^{5}$ Proponho o (re)verificar porque primeiro é preciso verificar o que já está estabelecido acerca dos conceitos propostos para então realizar uma reverificação, apresentando olhares outros para os conceitos de arte, cultura, educação, conhecimento e mediação cultural baseados em uma perspectiva descolonial.

${ }^{6}$ Essas questões se colocam levando em consideração que para mim as culturas são mediadas à medida que seja preciso proporcioná-las convivência. Ou seja, à medida que a mediação não ocorre, há guerras, uma sobrepõe-se às outras - opressor sobre oprimidos. Assim, entendo que a mediação tem um papel fundamental na escola, por exemplo, para proporcionar a equidade entre as construções culturais artísticas, especialmente, para demonstrar
} 
Foi percebido o caráter pedagógico da "mediação" desde minha primeira experiência, que aconteceu em parceria com o Festival do Teatro Brasileiro e escolas estaduais públicas de Campo Grande/MS. Enquanto professora de Arte percebi que aquela era uma ação que deveria partir da escola, e mais especificamente, nas aulas de Arte, entendendo que a escola participa de grande parte da formação do sujeito. ${ }^{7}$ E como professores de Arte poderíamos proporcionar aproximações entre os estudantes e os artistas, junto às suas produções artísticas, e principalmente de artistas locais. Para isso se faz relevante considerar noções acerca de conceitos e funções importantes a este processo.

Para (re)verificar o conceito de mediação cultural é preciso fazê-lo também com os conceitos de Arte, Cultura, Educação e Conhecimento. Ainda encontramos noções de tais conceitos respaldadas pela modernidade/colonialidade, por um discurso instaurado pelo eurocentrismo, de uma perspectiva de conhecimentos específicos "que se torna mundialmente hegemônico colonizando e sobrepondo-se a todas as demais, prévias ou diferentes, e a seus respectivos saberes concretos, tanto na Europa como no resto do mundo" (QUIJANO, 2005, p. 126). Já o conceito de modernidade aqui mencionado e inspirado por Aníbal Quijano (2005, 2009) está arrolado, no mundo capitalista, como única racionalidade válida, pensada e imaginada como experiência e produto exclusivamente europeus, de onde eles se imaginaram e pensaram toda a espécie humana, e como difundiram e estabeleceram essa perspectiva única como hegemônica dentro do padrão de poder mundial.

A colonialidade é o elemento específico do poder capitalista, tem relação direta com o capitalismo e um de seus eixos fundamentais é a imposição de uma classificação racial/étnica da população como padrão. A partir da ideia de colonialidade/modernidade eurocêntrica, criou-se uma concepção de humanidade, onde a população foi dividida em superiores e inferiores, racionais e irracionais, modernos e tradicionais, civilizados e primitivos, os tão insistentes dualismos que perduram na contemporaneidade (QUIJANO, 2009).

O eurocentrismo está no imaginário social onde o sujeito colonizado produz conhecimento somente a partir de tal imaginário instaurado, fala de um lugar de subalterno, mas não o reconhece como lócus enunciativo. Então fala e produz a partir do imaginário de

que são as diferentes histórias e geografias, igualmente sujeitos que precisam ser contemplados na disciplina de Arte para proporcionar interatividade (convivialidade) entre os membros da comunidade escolar.

\footnotetext{
${ }^{7}$ Aqui estou retomando, ou fazendo retornar, a ideia da escola como espaço privilegiado para a construção de conhecimentos. Uma construção que deve se dar na dialética: sujeito cultural e conteúdo programático; fundamental para o crescimento social, cultural, mas também crítico, político e econômico desse indivíduo na sociedade. Ao certo, parece, muitas vezes, não ser a escola que temos presente hoje nas sociedades.
} 
colonizado, de um imaginário hegemônico, do imaginário do colonizador. Sendo assim, o sujeito sob a colonialidade do poder não se reconhece como produtor de arte, cultura, educação e conhecimento se não estiver falando a partir do lugar do dominador, que está estabelecido por um controle de poder.

Encontramos reflexos da colonialidade/modernidade/eurocentrismo em currículos e referenciais do Ensino de Arte na Educação Formal. A História da Arte ainda referencia o trabalho dos professores de Arte do Estado de Mato Grosso do Sul, e assim não há um autorreconhecimento do estudante com o conteúdo ministrado. O Ensino de Arte, na maioria dos casos, ainda é realizado a partir do olhar do colonizador e dificilmente há espaço para o sujeito "subalterno" - aqui o estudante - produzir arte, cultura e conhecimento a partir de si.

E no caso da escola essa divisão também se comprova quando percebemos as diferenças entre conteúdos, professores, estruturas, entre outras características, distintas porque determinada escola está situada em bairros periféricos ou em zonas mais nobres das cidades brasileiras. Ainda que sejam escolas públicas é possível perceber a colonialidade imperante quando se comprova a falta de professores de determinadas disciplinas; a incapacidade da infraestrutura básica para aulas de Arte ou de Educação Física, por exemplo, mas também não existem laboratórios para as aulas de Ciências. Além da precariedade, evidente, no material didático, na deficiência entre as relações sociais da escola enquanto espaço institucional e a sociedade escolar: estudante e comunidade. Logo, nem é preciso falar do abismo enorme que se cria nas instituições que são da cadeia empresarial privada!

A colonialidade do poder criou uma episteme sedutora, impondo uma colonialidade do saber sobre aqueles que não eram europeus, "evidenciou-se também uma geopolítica do conhecimento, ou seja, o poder, o saber e todas as dimensões da cultura definiam-se a partir de uma lógica de pensamento localizado na Europa" (OLIVEIRA; CANDAU, 2010, p. 21). Deparamo-nos mais uma vez com a necessidade de pensar a Arte-mediação a partir da (re)verificação dos conceitos já postos, como visto, pela colonialidade do poder, de arte, cultura, educação e conhecimento, a partir de uma perspectiva descolonial, pois esses conceitos estão sempre pensados a partir de uma definição já instaurada pelo pensamento eurocêntrico, branco e fálico, sem desejar que a descolonização seja uma metodologia, mas sim, uma possibilidade como forma de pensar.

A colonialidade do saber instaura um lugar específico de produção de conhecimento, datado historicamente, com ascensão de lógica cumulativa e reprodutiva, para os lugares “descobertos" pela colonialidade do poder que engendra dominação e submissão dos que são diferentes. Quer dizer: somente produz conhecimento, apenas é possível produzir ciência, 
aquele homem, branco e de classe social alta que frequenta as melhores escolas que, por conseguinte, lhe dá os melhores acessos, e que tem data e lugar estabelecidos. Ao certo, portanto, toda sua história de produção de arte, de cultura, de conhecimentos necessariamente deve ser transmitida e perpetuada pelos conteúdos escolares às classes minoritárias social, cultural, econômica e politicamente compreendidos como inferiores por aqueles.

Como diria Walter Mignolo (2008) para aprender a desaprender os conceitos de arte, cultura, educação e conhecimento, faz-se necessária uma descolonização, ou melhor dizendo, uma desobediência epistêmica. Somente assim poderá ser possível um desencadeamento epistêmico para não permanecer no domínio dos conceitos modernos e eurocentrados. A opção descolonial, que é epistêmica, se desvincula de conceitos ocidentais e da acumulação de conhecimentos já estabelecidos (MIGNOLO, 2008). Nota-se que os conceitos de professor de Arte, estudante e conteúdo ainda estão pautados nessa perspectiva moderna, ainda estão dominados pelos conceitos estabelecidos pela Europa, e os conteúdos do Ensino de Arte ainda tratam de conhecimentos acumulados ao decorrer do tempo.

Bessa-Oliveira (2017, p. 1884) vai mais afundo ao afirmar que

Para não continuarmos inscrevendo a Arte, a Educação e a Cultura em lugares desconhecidos, carecemos reconhecer o "nosso mundo", ou os nossos muitos mundos; o lugar de onde falamos ou produzimos arte e conhecimentos, primeiro, e, por conseguinte, devemos compreender que cada um dos nossos alunos tem uma apreensão desse mundo pautada em seu universo particular.

Vemos o reflexo da noção de arte, cultura, educação e conhecimento eurocêntricos na relação entre professor, estudante, conteúdo e contexto escolar, tornando a convivência entre esses cada vez mais distante. O professor está posto como o detentor de todo conhecimento e superior ao estudante, este considerado papel em branco, sentado em cadeiras enfileiradas para apenas receber conteúdos e conhecimentos. Conteúdos que são enrijecidos e baseados numa noção eurocêntrica e hegemônica, distante da realidade dos estudantes, apresentada pela formação dos professores.

Vemos a problemática já na formação dos professores de Arte, em que os conteúdos disciplinares das licenciaturas estão também enraizados na História da Arte europeia e na perspectiva da colonialidade/modernidade/eurocentrismo. Os professores em formação aprendem a história contada pelo colonizador e, automaticamente, reproduzem-na para os estudantes. Como se esses últimos fossem depósitos vazios que precisam ter acondicionados conhecimentos melhores porque têm lugar e tempo histórico privilegiados porque foram estratificados por homens, brancos, ricos, de fé católica, falantes de línguas estrangeiras reconhecidas como oficiais e universais e que dominam o fazer ciência. 
Acerca da formação dos estudantes, Flavio Desgranges $(2006,2008)$ trata sobre o acesso físico e acesso linguístico e mais à frente sobre formação de público e formação de espectadores. O acesso físico está relacionado a toda ação e iniciativa que viabilizem aos espectadores o acesso à obra e dialoga com a ideia de formação de público que deseja ampliar os frequentadores das produções artísticas. É quando eu facilito o acesso físico, como, por exemplo, ao levar um grupo de indivíduos para um espetáculo de teatro, levar espetáculos para escolas ou o barateamento de ingressos, tenho aí possíveis caminhos para ampliação desse público.

Essa ação acaba por buscar caminhos com o objetivo de ampliar o público apreciador de arte de determinado local, o que não significa que o espectador terá um encontro íntimo com a arte, com o artista apresentado. O que pode por acabar promovendo o que aconteceu em determinado espetáculo que participei como espectadora, em que os estudantes haviam ido ao teatro, mas a grande maioria deles ou estava conversando ou estava mexendo no celular. O público das escolas não aparentava estar dialogando com a proposta do espetáculo, mas tinham tido acesso ao espaço cênico e ao espetáculo de dança. ${ }^{8}$

Já o acesso linguístico trata-se do estímulo da conquista da autonomia crítica e criativa do espectador em relação à obra. Assim, esta autonomia se faz necessária para que o espectador crie seu próprio percurso para aproximar-se dos elementos da obra em seus aspectos sensíveis e reflexivos; o que dialogará com a formação de espectadores que visa tratar das individualidades, promover um acesso mais íntimo entre espectador e obra, além de estimular que o espectador tenha proveitoso diálogo e uma experiência intensa com o espetáculo (DESGRANGES, 2008).

A formação de espectadores dialoga diretamente com minha proposta de pesquisa e de prática, assim como com a Arte-mediação, pois, além de proporcionar o acesso físico aos estudantes, desejo proporcionar o acesso linguístico, ou seja, que o estudante dialogue com a obra artística. Isso acontece quando proporciono a esses estudantes experiências corporais e reflexões a partir de determinada obra artística, que de alguma forma farão parte de seu repertório para construção de sentidos da obra a ser apreciada, considerando a memória, as experivivências dos estudantes anteriores à apreciação e à mediação, tendo em vista que o Arte-mediador não visa à educação do estudante como um "saco vazio" sem qualquer informação.

\footnotetext{
${ }^{8}$ Nesse sentido cabe a questão: como criar público para apreciação de espetáculos ou obras artísticas? Educando ou mediando aqueles com esses?
} 
Para isso é importante ressaltar aos estudantes que a construção de sentidos se dará a partir de quem eles são e de suas experiências, ou seja, ressaltar a autonomia crítica e criativa do estudante enquanto espectador. Isso deverá ser feito sem direcionar seu olhar ou estabelecer os sentidos que deverão ser construídos, mas afirmando que estes estudantes, enquanto apreciadores, são produtores de arte, de cultura e de conhecimento a partir de suas próprias experiências e de quem eles são. Dessa forma a Arte-mediação promoverá aproximações entre os estudantes e os artistas a partir do momento em que forem aproximados também do professor e dos conteúdos apresentados no ensino de Arte.

Bessa-Oliveira (2017, p. 1881), após contextualizar o que entende por ensino, vai dizer que "ensinar/educar arte e cultura é completamente oposto à ideia de transferir conhecimento com arte e cultura", e a partir daí, também vai afirmar que os professores não ensinam, mas realizam uma transferência/troca do conhecimento:

Nós transferimos, somos transferidos por, e conduzimos os conhecimentos com a
arte e cultura para os alunos. Sejam os conhecimentos históricos, aqueles que estão
postos pelos Referenciais Curriculares; sejam os conhecimentos produzidos a partir
dos conhecimentos que os próprios alunos trazem de casa, cotidianos, das relaçôes
[dos] seus mundos específicos. Sejam ainda os conhecimentos que nós
professores/sujeitos temos do mundo.

Percebemos que houveram mudanças na escola em toda sua estrutura, mas os estudantes mudaram mais rapidamente. "A configuração da escola que temos hoje se respalda em um modelo criado no final do século XIX, que se baseia na estruturação de grupos homogêneos que progridem por classes existindo uma correlação entre idade do aluno e seu nível de conhecimento" (REBOLO; BROSTOLIN, 2017, p. 101). Os autores confirmam tal tendência homogeneizadora do ambiente escolar que não condiz com a realidade dos estudantes, mas infelizmente é o que está posto no contexto escolar hoje.

A escola ainda é o espaço de formação, mas atualmente, do século XX para cá é uma formação tecnicista, mercadológica e agora, em pleno século XXI, voltamos mais no passado ainda porque a escola está sendo militarizada. Com isso quero dizer que a escola sempre esteve desvinculada do seu público alvo, estudantes que têm acessos a coisas diferentes dos conteúdos programáticos e programados por sistemas (Públicos ou Privados) que não estão vinculados às realidades dos jovens estudantes. Formar visando ao mercado de trabalho não é construção de conhecimento, é castração de saberes culturais não hegemônicos.

Mesmo na Educação Infantil encontramos a tendência homogeneizadora e a visão moderna/colonial/eurocêntrica instaurada no imaginário do ambiente escolar. As apresentações realizadas pelas crianças, desde os seis meses aos cinco anos, são sequências coreografadas pelos professores. Essas apresentações, às vezes copiadas da internet, têm 
movimentos de braços balançando, com a professora - pois em sua maioria são mulheres dançando junto, utilizando movimentos que dificilmente fazem sentido para a criança ou que são gestos líricos: quando a música fala de amor ou coração, crianças fazem um movimento que representa o coração. Esperam-se, reivindicações feitas pela coordenação e direção da Instituição, que essas apresentações artísticas e as produções gráfico-plásticas realizadas pelas crianças sejam "bonitas". Ou seja, mesmo no imaginário social, ainda estão instaurados conceitos eurocêntricos e dicotômicos do que é belo, ou não, onde os professores acabam por reproduzir modelos prontos e já aprovados pela perspectiva europeia ou norte-americana comprovando que seus planos de aulas e currículos são também coloniais e colonizadores.

\section{Arte-mediação: aproximações e produção de saberes}

Flavinês Rebolo e Marta Regina Brostolin (2017, p. 100) afirmam que os saberes disciplinares "são importantes, mas a capacidade de criar formas diferenciadas de atuação é um recurso essencial para o professor. Portanto, torna-se urgente a promoção de um ambiente reflexivo propício ao desenvolvimento e expressão da criatividade no contexto escolar". As autoras prosseguem alegando que na sociedade contemporânea o repasse dos conteúdos que foram acumulados historicamente e o preparo para o mundo trabalhista são muito pouco em vista do compromisso que a escola deve ter com a formação do estudante.

Os conteúdos acumulados historicamente não dão mais conta do Ensino hoje, os estudantes de hoje não são mais os mesmos de quando tais conteúdos foram inventados e aplicados para assim serem repassados na educação, visto que os estudantes estão em constante transformação, assim como nossa sociedade. Por isso é necessário (re)verificar e trabalhar com a Arte-mediação, que além de aproximar os estudantes dos artistas e suas produções, visa aproximar os conteúdos da realidade dos estudantes, pensar o trabalho de Arte a partir deles, de forma que possam dialogar. E é possível compreender porque hoje nas aulas de Arte não há essa relação dos estudantes com os conteúdos, como bem ilustra Marcos Bessa-Oliveira (2017, p. 1886):

As leituras da arte e da cultura locais como obras Clássicas e Modernas não aproximam as obras históricas ou as produções contemporâneas aos alunos. O que é feito por eles acaba não sendo aceito como produção de arte, cultura e conhecimentos, isso desvincula aquela Arte Maior das suas práticas artísticas. Assim, o aluno não consegue, com as atuais aulas de Artes, vislumbrar relação entre aquela Obra de Arte distante, histórico, geográfico e culturalmente, com seus raps, grafites, funks, skats (falo do skate porque é tanto prática esportiva como o é cultural), ou com o hip hop que estão desenvolvendo nas comunidades (BESSAOLIVEIRA, 2017, p. 1886).

Desejo com a Arte-mediação afirmar esse estudante como produtor de conhecimento, de arte e de cultura, e para isso é preciso (re)verificar a prática do professor em sala de aula e sua 
relação com o conteúdo e a transferência de conhecimentos, como já visto anteriormente. E para isso será necessário dar voz ao indivíduo, "[...] fazer valer a biogeografia, a experivivência de cada um desses corpos é fazer valer o direito a voz, vez, lugar, à produção de arte, cultura e conhecimentos das interioridades desses muitos corpos descartados" (BESSA-OLIVEIRA, 2018, p. 11).

A Arte-mediação ao desejar a aproximação entre professor e estudante entende que para que isso aconteça é preciso que o professor de Arte reconheça e considere a biogeografia desses estudantes. Quando o professor não dá voz ao estudante acaba por reforçar o distanciamento entre eles, e automaticamente entre os conteúdos ministrados. Mais uma vez, é fundamental que o professor de Arte reconheça o estudante como produtor de arte, cultura e conhecimento a partir de suas experivivências.

Valho-me da "ecologia de saberes" de Boaventura de Sousa Santos em que é possível o diálogo científico com todos os outros conhecimentos. Na ecologia de saberes, a ciência sempre estará presente, onde a partir do material produzido pelo senso comum será possível construir um conhecimento rigoroso (BOAVENTURA; HISSA, 2011, p. 20). Sendo assim, a Arte-mediação vai se valer dos saberes que os estudantes apresentam, assim como os saberes produzidos no local onde este se encontra, aqui, Campo Grande, Mato Grosso do Sul, lócus que também produz saberes diferentes dos estabelecidos pela colonialidade/modernidade/eurocentrismo, mas que também se relacionarão com os saberes científicos estabelecidos pelo currículo, possibilitando a construção de conhecimentos.

É do lugar em que os estudantes e o professor de Arte se encontram que será construído o Ensino de Arte, e assim, a Arte-mediação. "No lugar é onde se dá a existência vida cotidiana, econômica, cultural, política - onde o mundo se expressa de diversas maneiras. Nos lugares existem, mais fortemente, as possibilidades de diálogos" (MAIA; HISSA, 2011, p. 36). A Arte-mediação com a ideia de possibilitar aproximações entre estudante, professor de Arte, conteúdos, artistas e suas produções, reconhece que será a partir do lócus de enunciação de cada um desses que diálogos poderão ser estabelecidos e saberes serão produzidos.

A perspectiva da Arte-meidação considera as diferentes subjetividades dos indivíduos para produzir conhecimentos, sensibilidades, experivivências outros que não estão e não são aplicados aos/nos corpos. Estou propondo a ideia, por meio da Arte-mediação, de construirmos uma escola em que as diferenças convivem e não sobrevivem como em um campo de guerras cotidiano. Quero, por meio da Arte-mediação, levar aquele/a que não dança 
a dançar, aquele/a que não pinta a pintar, aquele/a que nunca apreciou um espetáculo de teatro a fazê-lo. Pois, afinal, sensibilidade e coração são iguais a cérebro, cada um tem os seus!

\section{Arte-mediação: uma proposta outra para o Ensino de Arte}

A proposta desse trabalho foi a de (re)verificar os conceitos de Arte, Cultura, Educação, Conhecimento e de Mediação Cultural, assim como as relações entre estudante, professor e conteúdo, propondo a Arte-mediação como epistemologia para o ensino de Arte. Tal (re)verificação há de ser feita em uma perspectiva descolonial, entendendo que tais conceitos e relações ainda estão instaurados e estabelecidos pela colonialidade/modernidade/eurocentrismo.

Mas "fazer" descolonialmente não quer dizer teorizar descolonial. Estou também propondo um modos outro de viver a vida. Um modo que passa pela compreensão de que o "outro" é uma construção imagética do pensamento eurocêntrico para se prevalecer como o "Eu". Uma maneira de perceber que nas menores coisas de uma vida específica estão as práticas mais importantes que devem ser socializadas para promoção da convivência em estado de diferença. Falo do respeito aos direitos, à democracia, à política e igualmente a saúde, segurança e a uma educação (como construção de conhecimentos outros) de qualidade. Portanto, esse aparato não está nas mãos nem dos teóricos e menos ainda nos documentos oficiais do estado-nação ou nas assinaturas das grandes, médias ou pequenas (talvez esta última um pouco menos) corporações.

A Arte-mediação deseja, a partir dessas (re)verificações, promover a aproximação entre os estudantes, professores de Arte e os conteúdos por meio das sensibilidades biogeográficas (BESSA-OLIVEIRA, 2017). Com essa aproximação será possível também promover a aproximação entre os estudantes e os artistas juntamente com suas produções, considerando a formação de espectadores proposta por Desgranges (2006, 2008), possibilitando assim o diálogo entre saberes que cada sujeito carrega e então a construção do ensino e aprendizagem em Arte.

E indo mais além, deseja-se provocar esses estudantes a desconstruir este pensamento do que é bom e/ou certo, ou o que é conhecimento, arte, cultura e educação já posto pela perspectiva do centro e mais, a pensar a partir de quem eles são, de sua própria história, reconhecendo-se como produtores de conhecimento, de arte e como indivíduos culturais. E é natural o estudante não levar isso em consideração. Pois pelo que já vimos, não se está interessado em saber o que este estudante pensa, principalmente ao falar de um estudante da escola pública, periférica, que tem um ensino centrado num saber técnico e científico. 
Com o trabalho do professor como Arte-mediador em aula, na esteira de Hissa (2011), temos a oportunidade de estimular esse estudante a cada vez mais se tornar pertencente ao lugar em que ele se encontra, a tomar posse desse lócus, como foi tratado no início deste trabalho. Temos a oportunidade de provocar esse aluno a ver que "o lugar é feito de nós, das nossas representações, dos nossos cotidianos, do simbólico que a ele se entrelaça, das subjetividades, das emoções, das sociabilidades, do afeto, da solidariedade" (HISSA, 2011, p. $51)$.

Para que todas essas (re)verificações propostas aqui ocorram, na esteira de BessaOliveira (2017), nós, sujeitos envolvidos nessa desobediência epistêmica, precisaremos ser, saber e sentir o "mundo" do qual fazemos parte. Ao nos reconhecermos assim, será possível criar uma relação entre professor, estudante, educação e conhecimento para a construção de conhecimentos através da Arte, da Arte-mediação.

\section{Referências}

BESSA-OLIVEIRA, Marcos Antônio. Enquanto esse velho trem atravessa... Biogeografias para descolonizar o ser, sentir e saber no ensino de artes visuais. In: CONFAEB - XXVII Congresso Nacional da Federação de Arte/Educadores do Brasil ; V Congresso Internacional dos Arte/Educadores ; II Seminário de Cultura e Educação de Mato Grosso do Sul, 2017, Campo Grande, MS. XXVII Congresso Nacional da Federação de Arte/Educadores do Brasil ; V Congresso Internacional dos Arte/Educadores ; II Seminário de Cultura e Educação de Mato Grosso do Sul. Campo Grande, MS: Federação de Arte/Educadores do Brasil, 2017. v. 1. p. 1878-1890.

BESSA-OLIVEIRA, Marcos Antônio. (De)corposição - carvão e tinta em corponeg(r)ado exposição de desenhos e pinturas. In: Anais da Jornada de Artes da UEMS 2018: para que serve o ensino das artes na escola?. Anais. Campo Grande (MS) UEMS - Universidade Estadual de Mato Grosso do Sul, UUCG - Unidade Universitária Campo Grande, 2018. Disponível em: <https//www.even3.com.br/anais/jart/108737-(DE)CORPOSICAO-CARVAO-E-TINTA-EM-CORPONEG(R)ADO--EXPOSICAO-DE-DESENHOS-EPINTURAS $>$. Acesso em: 14/10/2018

CANDAU, Vera Maria. Multiculturalismo e educação: desafios para a prática pedagógica. In: MOREIRA, Antonio Flávio, CANDAU, Vera Maria (Orgs.). Multiculturalismo: diferenças culturais e práticas pedagógicas. 10. ed.. Petrópolis, RJ: Vozes, 2013, p. 13-37.

DESGRANGES, Flávio. Pedagogia do teatro: provocação e dialogismo. São Paulo: Hucitec, 2006. 
DESGRANGES. Mediação teatral: anotações sobre o projeto Formação de Público. In: Urdimento. Florianópolis: Programa de Pós-Graduação em Teatro / CEART/UDESC, v.1, n. 10,2008 , p. $75-83$.

FILLER, Zina. Mediação para dança contemporânea: um primeiro desafio para gestores, artistas e instituições culturais. In: Revista do centro de pesquisa e formação. São Paulo: Nov/2015. P. 135-145.

HISSA, Cássio E. Viana. (Org.). Conversações: de artes e de ciências. Belo Horizonte: Editora UFMG, 2011. (Humanitas).

MIGNOLO, Walter D.. Desobediência epistêmica: a opção descolonial e o significado de identidade em política. Traduzido por: Norte, Ângela Lopes. In: Cadernos de Letras da UFF - Dossiê: Literatura, língua e identidade, no 34, p. 287324, 2008. Disponível em:

http://www.uff.br/cadernosdeletrasuff/34/traducao.pdf - acessado em: 14 de outubro de 2018.

QUIJANO, Aníbal. Colonialidade do poder, Eurocentrismo e América Latina. In: CLACSO, Consejo Latinoamericano de Ciencias Sociales. A colonialidade do saber: eurocentrismo e ciências sociais. Perspectivas latino-americanas. Buenos Aires, 2005, p. 117-142. Disponível em:

http://bibliotecavirtual.clacso.org.ar/clacso/sursur/20100624103322/12_Quijano.pdf acessado em: 13 de outubro de 2018

QUIJANO, Aníbal. Colonialidade do poder e classificação social. In: SANTOS, Boaventura de Sousa Santos, MENESES, Maria Paula (Orgs). Espistemologias do Sul. Coimbra: Edições Almedina, 2009. p. 73-117.

REBOLO, Flavinês; BROSTOLIN, Marta Regina. Aprendendo a ser professor na contemporaneidade: os desafios de uma prática reflexiva e criativa. In: SANTINHO, Gabriela Di Donato Salvador, BESSA-OLIVEIRA, Marcos Antônio, CARVALHO, Patrícia Alves. Diversidade e arte na formação docente. Campo Grande, MS: Life Editora, 2017. p. 97-109. 